\title{
Metabolic Engineering to Develop a Pathway for the Selective Cleavage of Carbon-Nitrogen Bonds
}

\author{
ANNUAL TECHNICAL REPORT
}

(October 2004-September 2005)

Principal Investigator: John J. Kilbane II

847-768-0723, john.kilbane@gastechnology.org

Report Issue Date: October 2005

DOE Contract No.: DE-FC26-02NT15382

Submitted by

\section{GAS TECHNOLOGY INSTITUTE}

1700 South Mount Prospect Road

Des Plaines, Illinois 60018

GTI Project No. 15334

Submitted to

FETC AAD Document Control

U.S. Department of Energy

Federal Energy Technology Center

P.O. Box 10940, MS 921-143

Pittsburgh, PA 15236-0940

DOE Technical Project Manager: Kathy Stirling 


\section{DISCLAIMER}

This report was prepared as an account of work sponsored by an agency of the United States government. Neither the United States government nor any agency thereof, nor any of their employees, makes any warranty, express or implied, or assumes any legal liability or responsibility for the accuracy, completeness or usefulness of any information, apparatus, product, or process disclosed, or represents that its use would not infringe privately owned rights. Reference herein to any specific commercial product, process, or service by trade name, trademark, manufacturer, or otherwise does not necessarily constitute or imply its endorsement, recommendation, or favoring by the United States government or any agency thereof. The views and opinions of authors expressed herein do not necessarily state or reflect those of the United States government or any agency thereof. 


\begin{abstract}
The objective of the project is to develop a biochemical pathway for the selective cleavage of $\mathrm{C}-\mathrm{N}$ bonds in molecules found in petroleum. Specifically a novel biochemical pathway will be developed for the selective cleavage of $\mathrm{C}-\mathrm{N}$ bonds in carbazole.

The cleavage of the first $\mathrm{C}-\mathrm{N}$ bond in carbazole is accomplished by the enzyme carbazole dioxygenase, that catalyzes the conversion of carbazole to 2-aminobiphenyl-2,3-diol. The genes encoding carbazole dioxygenase were cloned from Sphingomonas sp. GTIN11 and from Pseudomonas resinovorans CA10. The selective cleavage of the second C-N bond has been challenging, and efforts to overcome that challenge have been the focus of recent research in this project. Enrichment culture experiments succeeded in isolating bacterial cultures that can metabolize 2-aminobiphenyl, but no enzyme capable of selectively cleaving the $\mathrm{C}-\mathrm{N}$ bond in 2aminobiphenyl has been identified. Aniline is very similar to the structure of 2-aminobiphenyl and aniline dioxygenase catalyzes the conversion of aniline to catechol and ammonia. For the remainder of the project the emphasis of research will be to simultaneously express the genes for carbazole dioxygenase and for aniline dioxygenase in the same bacterial host and then to select for derivative cultures capable of using carbazole as the sole source of nitrogen.
\end{abstract}




\section{TABLE OF CONTENTS}

EXECUTIVE SUMMARY …................................................................................................. 5

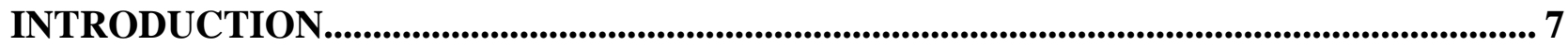

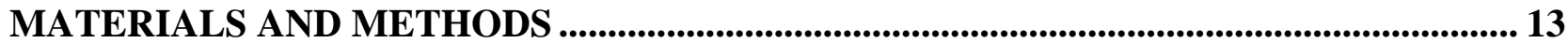

Bacterial Cultures and Growth Conditions ............................................................................. 13

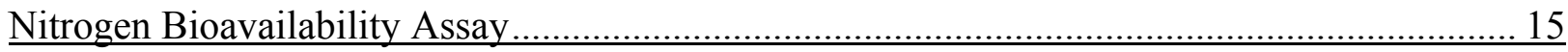

Thin Layer Chromatography for Identification of Metabolites ............................................ 17

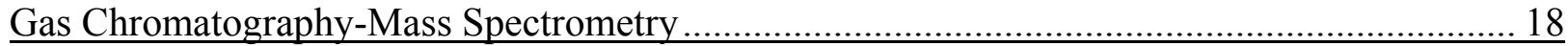

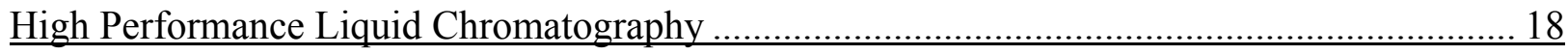

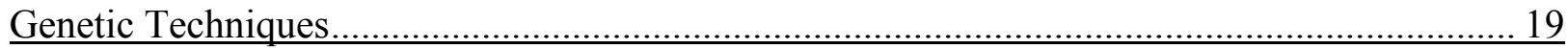

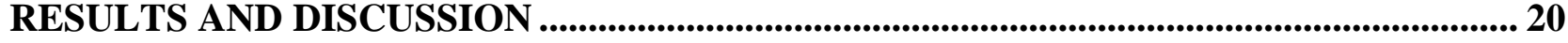

$\underline{\text { Selective Cleavage of Carbon-Nitrogen Bonds: Expression of CarA and AtdA in Rhodococcus }}$

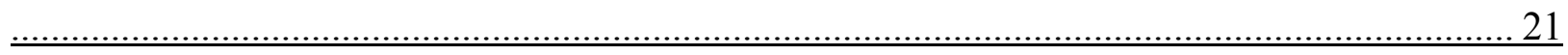

Expression of CarA in Rhodococcus …………………........................................... 22

Construction of a Derivative of Sphingomonas GTIN11 that Lacks CarB and CarC Enzymes

.

Isolation of 2ABP Degrading Bacterial Culture ................................................................. 28

Cloning and Expression of the atdA1-5 Genes for Aniline Dioxygenase .............................. 38

CONCLUSIONS AND FUTURE EXPERIMENTS ........................................................................ 39 
FIGURE 1. CARBAZOLE DEGRADATION PATHWAYS ........................................................ 10

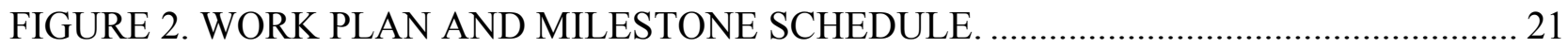

FIGURE 3. MAP OF RHODOCOCCUS EXPRESSION VECTOR PREP45BOXBNSIKAN...... 25

FIGURE 4. STRATEGY FOR THE REPLACEMENT OF THE CARBA, CARBB, AND CARC GENES OF SPHINGOMONAS GTIN11 WITH A GENE ENCODING KANAMYCIN RESISTANCE.

FIGURE 5. STRUCTURE OF ORGANONITROGEN COMPOUNDS USED IN GROWTH

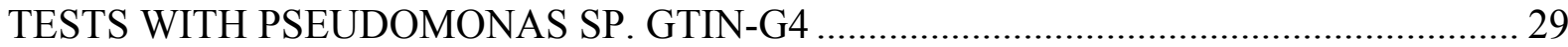

FIGURE 6. MASS SPECTRA OF 2-AMINOBIPHENYL AND A METABOLITE PRODUCED

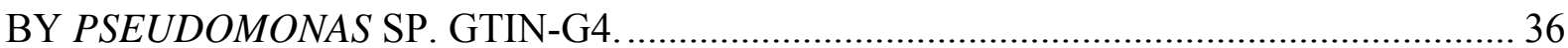

FIGURE 7. MASS SPECTRA OF O-TOLUIDINE AND DIPHENYLAMINE AND THE CORRESPONDING METABOLITES PRODUCED BY PSEUDOMONAS SP. GTIN-G4. 37

FIGURE 8. DEAMINATION AND OXYGENATION OF (A) ANILINE AND (B) OTOLUIDINE BY ATDA. 


\section{EXECUTIVE SUMMARY}

The objective of the project is to develop a biochemical pathway for the selective cleavage of C-N bonds in molecules found in petroleum. Specifically a novel biochemical pathway will be developed for the selective cleavage of $\mathrm{C}-\mathrm{N}$ bonds in carbazole. This is the second annual report in a 3-year research project and encompasses the period from October, 2004 to September, 2005.

The development of biocatalysts with improved ability to cleave carbon-nitrogen bonds is being addressed by cloning the genes for carbazole dioxygenase and aniline dioxygenase. The removal of nitrogen from aromatic compounds like carbazole requires the cleavage of two carbon-nitrogen bonds. The cleavage of the first carbon-nitrogen bond is accomplished by the enzyme carbazole dioxygenase while an enzyme capable of selectively cleaving the second carbon-nitrogen bond has not yet been identified. The enzyme carbazole dioxygenase is encoded for by three genes: carAa, carAc, and carAd. The carAacd genes have been cloned and sequenced from several different microbial cultures including Sphingomonas sp. GTIN11 and Pseudomonas resinovorans CA10. While an enzyme that can selectively cleave the second carbon-nitrogen bond in carbazole has not yet been identified a reasonable candidate for such an enzyme is the aniline dioxygenase from Acinetobacter sp. YAA. The genes that encode aniline dioxygenase (atdA1, atdA2, atdA3, atdA4, and atdA5) have been cloned. These genes will be expressed in Rhodococcus erythropolis, a bacterial host that tolerates exposure to petroleum. Gene expression vectors for use in Rhodococcus erythropolis are being constructed from plasmids pEBC26, pSRKgfp, and pRESQ.

Enrichment culture experiments designed to isolate a culture capable of cleaving the carbon-nitrogen bond in 2-aminobiphenyl, and thus being capable of providing an enzyme for the cleavage of the second carbon-nitrogen bond in carbazole, resulted in the isolation of a unique microbial culture Pseudomonas sp. GTIN-G4. Pseudomonas sp. GTIN-G4 is capable of metabolizing 2-aminobiphenyl and related compounds, but does not appear to be capable of cleaving the carbon-nitrogen bond. Instead it has the unprecedented ability to modify organonitrogen compounds by replacing a hydrogen bound to the nitrogen atom with a formaldehyde group. This is a very interesting metabolic ability, but it does not allow the removal of nitrogen from organonitrogen compounds so this culture will not be examined further. 
The time remaining in this project does not allow for continued enrichment culture experiments seeking to identify an enzyme capable of selectively cleaving the C-N bond in 2aminobiphenyl. Accordingly, future experiments will utilize enzymes/genes that are cloned and available to the project, and known to be capable of selectively cleaving $\mathrm{C}-\mathrm{N}$ bonds in substrates that are chemically similar to carbazole and its metabolites. The focus of research will be on constructing a new metabolic pathway for the selective cleavage of $\mathrm{C}-\mathrm{N}$ bonds by expressing the genes for carbazole dioxygenase and for aniline dioxygenase in the same bacterial host, Rhodococcus erythropolis. Subsequent selection for growth under conditions where carbazole serves as the only source of nitrogen will hopefully result in the isolation of a novel biochemical pathway for the selective cleavage of $\mathrm{C}-\mathrm{N}$ bonds in carbazole. 


\section{INTRODUCTION}

With the decline in the production of light and medium weight crude oils, refineries will increasingly be forced to process heavier and sour crudes. These crude oils are high in sulfur, nitrogen and metals. Nitrogen and sulfur in petroleum can foul catalysts decreasing the efficiency of hydrotreating and catalytic cracking processes. Sulfur-containing compounds typically found in petroleum that are recalcitrant to removal by hydrotreating are dibenzothiophene and alkylated derivatives of dibenzothiophene. The heavier gas oils and residua contain both basic and non-basic nitrogen compounds. The basic nitrogen compounds include pyridine, quinoline, acridine, phenanthridine, and their derivatives. These are responsible for poisoning of FCC catalysts by the reaction of the basic compounds with the acidic sites of the catalyst. The non-basics are predominantly mixed alkyl derivatives of carbazole and account for $70-75 \%$ of the total nitrogen content of crude oil $(0.3 \% \mathrm{~N})$. The neutralization of the active acid sites results in deactivation of the catalyst. Nitrogen poisoning also affects the selectivity of the reaction. Carbazole, a major constituent of the non-basic portion (and hence of the total nitrogen present), gets converted into basic derivatives during the cracking process and adsorbs and poisons the catalyst as described above. Nitrogen compounds in petroleum foul catalysts and thus decrease the efficiency of the existing hydrotreating and catalytic cracking processes. In addition to catalyst fouling, nitrogen compounds also promote corrosion of the equipment. Also, the combustion of nitrogen compounds leads to formation of nitrogen oxides (NOx) which, in the presence of other hydrocarbons (VOCs:volatile organic compounds) and sunlight lead to ozone formation. Both ozone and NOx are hazardous to human health. Removal of these organonitrogen compounds will not only significantly improve the efficiency of the catalytic cracking process and result in cost savings for the refinery but also decrease atmospheric pollution. The selective removal of nitrogen from petroleum is a relatively neglected topic in comparison with sulfur removal. Moreover, most metals in oil are associated with nitrogen compounds, and nitrogen compounds contribute to the instability of petroleum byproducts[5, 13, 31]. The selective removal of nitrogen from oil would be highly desirable, but effective processes are not currently available.

There is hence a need to develop alternate cost-effective and energy-efficient technologies for the removal of sulfur, nitrogen and metals. Existing thermochemical processes, such as hydrodesulfurization, can efficiently remove much of the sulfur and nitrogen from 
petroleum but the selective removal of all organically bound sulfur and nitrogen, and the removal of metals cannot be efficiently accomplished using currently available technologies. The specificity of biochemical reactions far exceeds that of chemical reactions. Moreover biorefining can be performed at comparatively low temperatures and pressures and does not require hydrogen thus avoiding a significant amount of operating costs associated with the conventional hydrodesulfurization process. The selective removal of sulfur from dibenzothiophene and from petroleum by biochemical reactions performed by microorganisms has been demonstrated, but improved cultures are needed before a viable biodesulfurization process can be developed. Biorefining can also potentially be used to remove nitrogen and metals from petroleum, but so far this area of research has received very little attention.

Biorefining can complement existing technologies by specifically addressing compounds/contaminants refractory to current petroleum refinery processes. Heteroatoms such as nitrogen, metals, and sulfur can poison the catalysts used in catalytic cracking and hydrotreating processes[8, 12, 24, 31]. Existing refineries are not capable of operating efficiently with heavy crude oils and residuum that have high heteroatom content. Bioprocesses could be used to pre-treat oil reducing the heteroatom content allowing the use of heavy crude oils that could not otherwise be treated with existing refinery processes. Biorefining processes can also be used in conjunction with existing processes to meet the increasingly stringent environmental requirements for contaminant reduction. Additionally, most current technologies focus on the removal of sulfur while the development of processes to remove nitrogen, and its associated heavy metals, is a comparatively neglected research topic that will increase in importance as the quality of available petroleum declines[14].

There is currently no biochemical pathway, or thermochemical process, for the selective removal of nitrogen from compounds typically present in petroleum [8, 31]. Previous research by GTI characterized the biochemistry and the genetics of microbial enzymes capable of cleaving one of the two carbon-nitrogen bonds in carbazole[16]. This project extends that work by constructing a biochemical pathway enabling the selective and complete removal of nitrogen from carbazole and related compounds. Thus the successful completion of the project will provide a previously unavailable treatment option for the up-grading of petroleum. Moreover, demonstrating the construction of a novel biochemical pathway will guide future research in overcoming other obstacles for which no technically viable approach is currently available. 
Carbazole is a good model compound that is representative of the nitrogen-containing compounds present in the greatest abundance in many petroleum samples[5, 13, 19]. For developing a biological process for the removal of nitrogen from petroleum no known carbazoledegrading culture is particularly appropriate because nitrogen is only removed in the course of overall degradation[2, 11, 16-18, 20, 23, 25, 29, 30]. A microorganism capable of selectively cleaving $\mathrm{C}-\mathrm{N}$ bonds in quinoline and removing nitrogen from petroleum was isolated and characterized[15] (by GTI). But quinoline is not the predominant form of organonitrogen compounds in petroleum. What is wanted is selective cleavage of both C-N bonds in carbazole, and related compounds, resulting in the selective removal of nitrogen while leaving the rest of the molecule intact.

A variety of carbazole-degrading microorganisms have been reported in the literature including Sphingomonas, Pseudomonas, Mycobacterium, Ralstonia and Xanthamonas species[2, $11,16-18,21,26,27,29,30]$. Insofar as biodegradation pathways have been investigated, these differing species of carbazole degraders follow a similar carbazole degradation pathway that begins with the oxidative cleavage of the heterocyclic nitrogen ring of carbazole to form 2'aminobiphenyl-2,3-diol. This compound is then oxidized through meta cleavage yielding 2hydroxy-6-oxo-6-hexa-2e,4z-dienoate. The next metabolic steps result in the degradation of one of the aromatic rings releasing carbon dioxide. In existing pathways nitrogen is released from carbazole only after substantial carbon degradation. Figure 1 illustrates the carbazole degradation pathway employed by all currently known carbazole utilizing cultures as well as the pathway for selective removal of nitrogen from carbazole that will be created in this project.

Therefore several bacterial cultures are known that can utilize carbazole as a sole nitrogen source, but no culture is known that can selectively cleave both C-N bonds in carbazole while leaving the rest of the molecule intact. 

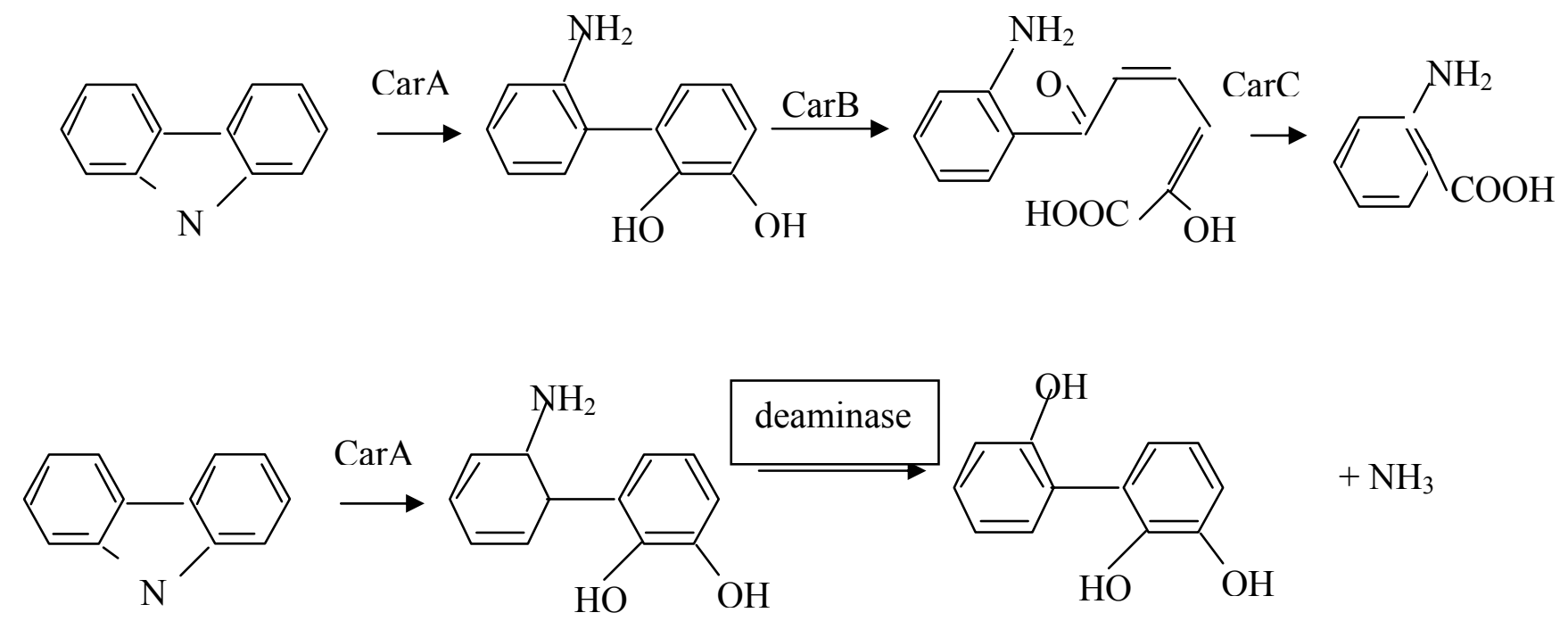

$+\mathrm{NH}_{3}$

FIGURE 1. CARBAZOLE DEGRADATION PATHWAYS.

The top pathway illustrates the existing carbazole degradation pathway that results in overall degradation, whereas the bottom pathway illustrates the pathway for the selective removal of nitrogen from carbazole that will be developed in this project.

Sphingomonas sp GTIN11 [16]was isolated by GTI scientists and demonstrated to metabolize carbazole, and to a lesser extent $\mathrm{C} 1$ and $\mathrm{C} 2$ derivatives of carbazole, from petroleum. Moreover, the genes encoding a portion of the carbazole degradation pathway of Sphingomonas sp. GTIN11 have been cloned and sequenced. The reaction catalyzed by CarA converts carbazole to 2'-aminobiphenyl-2,3-diol accomplishing the cleavage of the first $\mathrm{C}-\mathrm{N}$ bond in carbazole. There are no known deaminases that can metabolize 2'-aminobiphenyl-2,3-diol and accomplish the cleavage of the final $\mathrm{C}-\mathrm{N}$ bond[7, 9]. This project will use enrichment culture, and directed evolution to isolate and/or create a deaminase that will recognize 2'-aminobiphenyl2,3-diol as a substrate. The gene encoding an appropriate deaminase will be identified, sequenced, and combined with the carA genes (carAa, carAc, and carAd encoding for the 
carbazole dioxygenase, ferredoxin and ferredoxin reductase respectively) from Sphingomonas sp. GTIN11 and thereby construct a synthetic operon for the selective removal of nitrogen from carbazole, as shown in Figure 1. The carA genes from Sphingomonas sp. GTIN11 will be used in the proposed work because this is the only carbazole degrading culture demonstrated to remove nitrogen from petroleum. A preferred bacterial strain would lack the $\operatorname{carB}$ and $\operatorname{car} C$ genes[11, $25,29]$ so that complete biodegradation of carbazole would be avoided and the final product would be 2',2,3-trihydroxybiphenyl (or a similar compound).

Enrichment culture experiments will be performed to isolate bacterial cultures capable of utilizing 2-aminobiphenyl as a sole nitrogen source. Cultures will then be tested to determine if they contain an enzyme that can deaminate 2-aminobiphenyl. Because 2'aminobiphenyl-2,3-diol is not commercially available enrichment culture experiments will employ 2-aminobiphenyl. Known deaminases have limited ability to metabolize aromatic amides and their substrate range includes benzamide, toluamide, and anthranilamide[7, 9]. However, these enzymes can possibly by modified to recognize 2-aminobiphenyl as a substrate. Alternatively, the initial step in aniline degradation, catalyzed by aniline dioxygenase, is the conversion of aniline to catechol and ammonia. The chemical similarity between aniline and 2-aminobiphenyl make aniline dioxygenase a good candidate enzyme for potentially cleaving the $\mathrm{C}-\mathrm{N}$ bond in 2aminobiphenyl. Once bacterial cultures are available that can deaminate 2-aminobiphenyl, then the deaminase gene will be cloned, sequenced, and combined with the carA genes of Sphingomonas sp. GTIN11 to create a novel metabolic pathway for the selective cleavage of C$\mathrm{N}$ bonds. It will be verified that the newly constructed pathway confers the ability to selectively cleave both $\mathrm{C}-\mathrm{N}$ bonds in carbazole.

This project is relevant to the DOE's interests because it can contribute to greater efficiency in petroleum refining and can decrease environmental pollution due to the use of petroleum. Nitrogen in petroleum contributes to air pollution and decreases refinery efficiency by poisoning catalysts, but it is difficult to remove organically bound nitrogen without destroying the calorific value of the fuel. A key objective of the project is to develop biochemical pathways for the selective cleavage of $\mathrm{C}-\mathrm{N}$ bonds in molecules found in petroleum. The successful completion of this project will enable the development of a bioprocess to selectively remove nitrogen, and associated metals, from crude oil and residuum which will allow existing. refineries to process lower quality oils than they could not otherwise accept. The reduction of 
nitrogen and metals in petroleum will allow refineries to operate more efficiently. This will decrease costs and will protect the environment[24].

In North America alone over 3 trillion barrels of known petroleum reserves are largely untapped or underutilized because of their high sulfur/nitrogen/metals content and attendant viscosity problems[32]. Energy statistics indicate that the U.S. imports $65 \%$ of its oil demand[14]. New technologies, such as the proposed work, will allow a greater utilization of heavy oils and residuum while still maintaining refinery efficiency and environmental protection. The National Petroleum Refineries Association estimated the cost of meeting Clean Air Act regulations requiring a maximum sulfur content of $0.05 \%$ for diesel fuel by 1994 cost about $\$ 3.3$ billion in capital expenditures and $\$ 1.2$ billion in annual operating costs[14, 24]. Similar estimates for the removal of nitrogen and metals from heavy oils and residuum are not available. However, diesel is far easier to treat than heavy oils so that one would predict that the costs associated with upgrading heavy oils and residuum would be correspondingly higher. The removal of nitrogen and metals prior to combustion of petroleum also protects the environment by eliminating contaminants that would otherwise contribute to air pollution. 


\section{MATERIALS AND METHODS}

\section{Bacterial Cultures and Growth Conditions}

Environmental samples were obtained from petroleum and/or hydrocarbon contaminated soil. The environmental samples were used to inoculate nutristat and shake flask directed evolution/enrichment culture experiments to obtain cultures that may be suitable for the metabolism of organonitrogen compounds. A further description of the methodologies used in the isolation and characterization of bacterial cultures that can selectively cleave $\mathrm{C}-\mathrm{N}$ bonds can be found in recent publications by GTI: Kilbane II, J. J., A. Daram, J. Abbasian, and K. J. Kayser, 2002, "Isolation and characterization of Sphingomonas sp. GTIN11 capable of carbazole metabolism in petroleum" Biochemical \& Biophysical Research Communications 297: 242-248, and Kilbane II, J. J., R. Ranganathan, L. Cleveland, K. J. Kayser, C. Ribiero, and M. M Linhares, 2000, "Selective removal of nitrogen from quinoline and petroleum by Pseudomonas ayucida IGTN9m", Applied \& Environmental Microbiology 66: 688-693.

Multiple nutristats were set up employing a defined nitrogen-free mineral salts medium $(\operatorname{Mod} \mathrm{A})$ :

$\begin{array}{ll}\mathrm{KH}_{2} \mathrm{PO}_{4} & 0.37 \mathrm{~g} / \mathrm{L} \\ \mathrm{MgSO}_{4} .7 \mathrm{H}_{2} \mathrm{O} & 0.25 \mathrm{~g} / \mathrm{L} \\ \mathrm{CaCl}_{2} .2 \mathrm{H}_{2} \mathrm{O} & 0.07 \mathrm{~g} / \mathrm{L} \\ \mathrm{FeCl}_{3} & 0.02 \mathrm{~g} / \mathrm{L} \\ \text { Glucose/glycerol/succinate } & 20.0 \mathrm{~g} / \mathrm{L}\end{array}$

This medium was adjusted to $\mathrm{pH} 6.5$ to 7 and nitrogen was supplied in the form of an organonitrogen test compound in the $0.5-20 \mathrm{mM}$ concentration range. For the positive nitrogen control, $10 \mathrm{mM} \mathrm{NH}_{4} \mathrm{Cl}(0.535 \mathrm{~g} / \mathrm{L})$ was used.

An improved recipe for a defined mineral salts media, MMN, that yielded better growth of some bacterial isolates was also used. A mixture of glucose, glycerol, and succinate was employed as a carbon source to encourage the growth of a wide range of microbial species. The recipe of the improved nitrogen-free minimal media $\mathrm{MMN}$ is: 


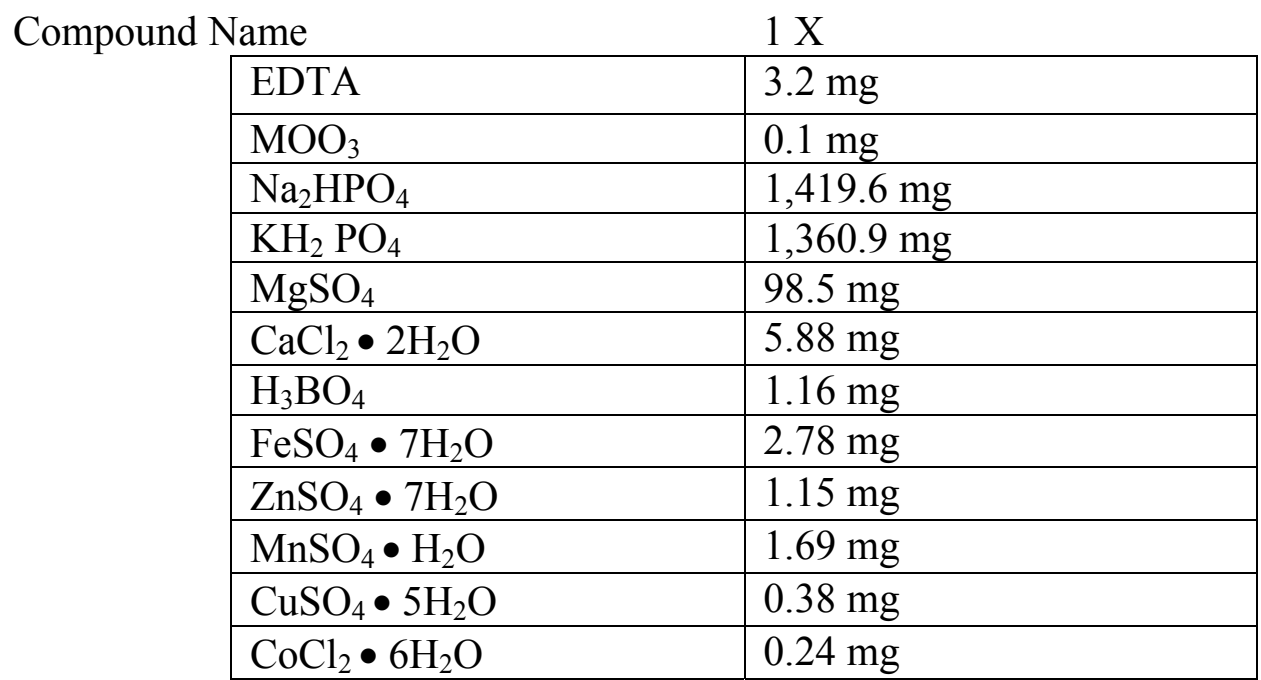

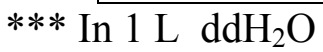

Nutristats and shake flasks were operated at temperatures of 25 (room temperature), 37, and $45{ }^{\circ} \mathrm{C}$. The working volume of nutristats is one liter and shake flask experiments generally utilize 25 to $100 \mathrm{~mL}$ of liquid medium. The organonitrogen test compound is routinely varied during the course of operation of the nutristats/shake flask experiments. Nutristats are operated in series so that the effluent of one nutristat serves as the influent for the next. Carbazole, 2aminobiphenyl, benzamide, aniline, 4,4'-azodianiline, ortho-, meta-, and para-toluidine, quinoline, pyridine, quinazoline, quinoxaline, piperidine, pyrolidine, triazine or other test compounds are added to the fresh media influent at concentrations of $0.5-20 \mathrm{mM}$. Flow rates of the nutristats are adjusted to achieve hydraulic retention times ranging from 35 hours to 60 hours. The flow rates and the organonitrogen test compound are altered as needed to ensure that the nutristats create an environment suitable for the selection of cultures with improved abilities to selectively cleave $\mathrm{C}-\mathrm{N}$ bonds. This means that the bacterial cell density in the nutristats/shake flasks ranges from $10^{2}$ to $10^{8}$ cells $/ \mathrm{mL}$, but generally cell densities of $10^{4}$ to $10^{5}$ cells $/ \mathrm{mL}$ are maintained. The bacteria isolated from the effluent of nutristats and/or from shake flasks or nitrogen bioavailability assays are subjected to short wave ultraviolet (UV) irradiation. Cell populations are mutagenized under conditions that result in the death of about $99 \%$ of the population. The mutagenized cells are then used to reinoculate nutristats, start additional shake flask experiments, and to streak onto agar plates containing organonitrogen test compounds. Care is taken to ensure that the amount of biomass that is added back to nutristats in the form of inocula is insufficient to provide a significant amount of nitrogen in the form of dead biomass. 
Hence significant bacterial growth in the nutristat experiments should be due to the utilization of nitrogen from the organonitrogen test compounds and not from readily available sources such as dead biomass. The effluent of nutristats and cells from shake flasks and from agar plates are routinely tested using the nitrogen bioavailability assay.

For the growth of desulfurization-competent bacterial cultures media that is deficient in sulfur was used. Two recipes for sulfur-free microbial growth media are given below.

\begin{tabular}{|l|l|l|}
\hline & BSM & MK1 \\
\hline $\mathrm{Na}_{2} \mathrm{HPO}_{4}$ & $5.57 \mathrm{~g} / \mathrm{L}$ & $4.00 \mathrm{~g} / \mathrm{L}$ \\
\hline $\mathrm{KH}_{2} \mathrm{PO}_{4}$ & 2.44 & 4.00 \\
\hline $\mathrm{NH}_{4} \mathrm{Cl}$ & 2.00 & 2.00 \\
\hline $\mathrm{MgCl}_{2}-6 \mathrm{H}_{2} \mathrm{O}$ & 0.20 & 0.20 \\
\hline $\mathrm{CaCl}_{2}-2 \mathrm{H}_{2} \mathrm{O}$ & 0.001 & 0.001 \\
\hline $\mathrm{FeCl}_{3}-6 \mathrm{H}_{2} \mathrm{O}$ & & 0.001 \\
\hline
\end{tabular}

\section{Nitrogen Bioavailability Assay}

The nitrogen bioavailability assay utilizes defined mineral salts medium in growth tests in which organonitrogen model compounds such as 2-aminobiphenyl, benzamide, aniline, 4,4'azodianiline, diphenylamine, maleimide, ortho-, meta-, and para-toluidine, quinoline, pyridine, carbazole, quinazoline, piperidine, pyrolidine, and triazine serve as sources of carbon and/or nitrogen. For selective cleavage of carbon-nitrogen bonds, a culture should be capable of utilizing an organonitrogen compound as a nitrogen source but not as a carbon source. Accordingly, growth tests are performed using the following eight conditions:

1. Test compound as sole source of carbon and nitrogen.

2. Test compound as sole source of carbon (alternative nitrogen source, ammonia, is available). 
3. Test compound as sole source of nitrogen (alternative carbon source, glucose/glycerol/succinate, is available).

4. Test compound present as well as alternative sources of carbon and nitrogen.

5. Only alternative nitrogen (ammonia) and carbon (glucose/glycerol/succinate) sources are available. The test compound is not present.

6. No carbon or nitrogen compounds of any kind are present.

7. Only alternative nitrogen (ammonia) is present. No carbon or test compound is present.

8. Only carbon (glucose/glycerol/succinate) sources are available. No nitrogen compounds (ammonia or test compound) are present.

These eight growth conditions constitute a bioassay for the ability of a culture to metabolize organonitrogen compounds. The basis of the nitrogen bioavailability assay is that all microorganisms require nitrogen for growth. When carbon and nitrogen sources other than the test compounds are needed, they will be supplied in the form of glucose/glycerol/succinate, and as ammonia respectively.

The nitrogen bioavailability assay described above can be performed with any organonitrogen test compound that is ordinarily used at a concentration of from 0.5 to $20 \mathrm{mM}$. The various cultures to be tested are inoculated into test tubes or shake flasks containing medium components appropriate for the eight test conditions. The cultures are then incubated aerobically for 2 to 28 days, at 25,37 , and $45^{\circ} \mathrm{C}$. The growth of the cultures is monitored easily by measuring the turbidity/optical density of the cultures in the various test conditions, or by determining colony-forming units. The unamended sample (test condition No. 6) serves as a negative control while the samples amended with both a carbon and nitrogen source (test conditions No. 4 and 5) serves as positive controls and should produce healthy microbial growth unless the test compound is toxic to the culture being tested. If the test compound is toxic only condition No. 5 should result in healthy growth. The amount of bacterial growth observed in test conditions 1, 2, and 3 in comparison with the amount of growth observed in test conditions 4, 5 and 6 , indicate the ability of cultures to use the organonitrogen test compound as a source of carbon and/or nitrogen. Those cultures which show better growth in test condition No. 3 than conditions Nos. 1 or 2 may be preferentially utilizing the organonitrogen compound as a nitrogen 
source only, and should be examined more thoroughly and included in further experiments. Conditions 7 and 8 serve as negative controls, and no growth should occur unless there is a problem with the batch of media used, or if the bacterial culture being tested has the ability to fix atmospheric nitrogen.

The ability of bacterial cultures to utilize organosulfur compounds as sole sources of sulfur needed for growth can be tested in a Sulfur Bioavailability Assay. It is performed in a manner similar to that described above for the Nitrogen Bioavailability Assay, but employs the sulfur-free media BSM or MK1.

\section{Thin Layer Chromatography for Identification of Metabolites}

Thin layer chromatography (TLC) was performed on Whatman Silica C-18 plates by the method described by Watson and Cain (Biochem. J. 146: 157-172, 1975). Running phase solvents used were chloroform-toluene (1:3), and hexane-acetic acid-xylene (5:1:2). Supernatants from bacterial cultures grown with an organonitrogen test compound as the sole source of nitrogen were obtained after centrifugation at $10,000 \times \mathrm{g}$ for 15 minutes. These supernatants were used at neutral or alkaline $\mathrm{pH}$. Typically $10 \mathrm{ml}$ of aqueous supernatant was acidified to $\mathrm{pH} 1$ to 2 with $\mathrm{HCl}$ and extracted with ethyl acetate $(1: 1$ or 1:0.5 v/v). The organic phase was separated from the aqueous phase by centrifugation or by using a separatory funnel. The ethyl acetate extract was then evaporated in a hood resulting in the concentration of the sample from 20 to 1000 -fold prior to the analysis of the extracts by TLC. 10 to $50 \mu \mathrm{L}$ of ethyl acetate sample that had been concentrated 100-fold relative to the volume of aqueous supernatant extracted was spotted onto TLC plates. Typical running times of the TLC plates were about 20 minutes. These plates were later observed under normal lighting, short (245 nm), and long wave (366 nm) UV light.

Some experiments also utilized resting cells that were prepared by centrifuging from 500 $\mathrm{ml}$ of log phase cultures grown with either an organonitrogen compound or ammonia as nitrogen sources. Then the washed cell pellets were resuspended in 5 to $50 \mathrm{ml}$ of mineral salts medium

achieving final cell densities of from $10^{10}$ to $10^{11}$ cells $/ \mathrm{ml}$. These cell suspensions were incubated with from 1 to $20 \mathrm{mM}$ test compound (organonitrogen compound) for periods ranging from 15 minutes to 24 hours. The incubator was agitated at about $200 \mathrm{rpm}$ and maintained at the 
microorganism's optimum temperature. The ethyl acetate extract was stored in amber vials at $4^{\circ} \mathrm{C}$ until they were analyzed by TLC, HPLC and/or GC-MS.

\section{Gas Chromatography-Mass Spectrometry}

GC-MS analysis was performed on extracts derived from growing and resting cell cultures exposed to organonitrogen test compounds, and on compounds eluted from spots observed on thin layer chromatography plates.

Extraction of the supernatants from resting cells as well as growing cells were carried out either by ethyl acetate solvent extraction or with C-18 solid phase extraction cartridges as described above for the preparation of samples for TLC analysis. Additionally, TLC spots of possible metabolites were scraped from the TLC plates and eluted with ethyl acetate and concentrated for analysis by GC-MS.

For analysis of the extracts a Hewlett Packard 5971 mass selective detector and 5890 series II GC with HP 7673 auto sampler tower and a 30 meter Rezteck XTI-5 column was used. The final oven temperature was maintained at $300^{\circ} \mathrm{C}$. The detection limit was $1 \mathrm{ng}$ or $1 \mu \mathrm{g} / \mathrm{ml}$ with a $1 \mu$ injection. Mass spectrographs were compared with various libraries of mass spectrograph data prepared from known standard compounds. Several chromatograph libraries were consulted to determine the identity of metabolites of organonitrogen compounds. The presence or absence of nitrogen in various compounds was also determined by GC-AED using the nitrogen-specific wavelength of $174.2 \mathrm{~nm}$ for detection.

Some samples were derivatized with trimethylsilane (TMS) prior to analysis by GC-MS. The TMS-silylating reagent was prepared using 9 parts pyridine, 3 parts hexamethyldisilizane (Sigma-Aldrich catalog \# 440191), and 1 part chlorotrimethylsilane (Sigma-Aldrich catalog \# C72854). Approximately $25 \mathrm{mg}$ of a sample (3 drops of ethyl acetate extract) was added to $2 \mathrm{~mL}$ of TMS-silylating reagent under anaerobic conditions. The mixture was agitated/mixed and allowed to incubate at room temperature for 30-60 minutes. The samples were centrifuged and the supernatants were used for GC-MS analysis.

\section{High Performance Liquid Chromatography}

The extracts derived from growing and resting cell experiments were analyzed by HPLC. Extraction was carried out with ethyl acetate as described in the TLC section. The ethyl acetate was then evaporated completely and the residue (nonvolatile organics) was suspended in 
acetonitrile before injecting into the HPLC system. A Waters system equipped with a Symmetry $\mathrm{C}_{18}(3.5 \mu \mathrm{m}, 4.6 \times 100 \mathrm{~mm})$ column and a 600 controller was used for this purpose. Detection of compounds was carried out using a 996 photodiode array detector coupled to the HPLC system. An isocratic mobile phase of acetonitrile:water at the flowrate of $1.5 \mathrm{ml} / \mathrm{min}$ was used as the running solvent.

\section{Genetic Techniques}

Methods used in genetic experiments are described in detail in the recent publications from GTI's biotechnology laboratory:

"New Host Vector System for Thermus spp. Based on the Malate Dehydrogenase Gene", K. J. Kayser and J. J. Kilbane II, Journal of Bacteriology 183: 1792-1795. (2001)

"Inducible and Constitutive Expression Using New Plasmid and Integrative Expression Vectors for Thermus sp.” K. J. Kayser, J.-H. Kwak, H.-S. Park, and J. J. Kilbane II. Letters in Applied Microbiology 32: 1-7 (2001).

Electroporation of Rhodococcus erythropolis

1. Grow cells in $\mathrm{NZ}$ for $24-48$ hours at $30^{\circ} \mathrm{C}$.

2. Dilute $1 / 5$ in fresh NZ, (50 $\mathrm{ml}$ total volume).

3. Grow at $30^{\circ} \mathrm{C}$ until $\mathrm{OD}_{600}$ of 0.6.

4. Harvest by centrifugation at $4^{\circ} \mathrm{C}$ and wash 4 times with $1.0 \mathrm{ml}$ ice cold $0.3 \mathrm{M}$ sucrose.

5. Resuspend cells in $1.0 \mathrm{ml} 0.5 \mathrm{M}$ sucrose.

6. Add $100 \mu \mathrm{l}$ of cells to ice cold $0.2 \mathrm{~cm}$ electroporation cuvette, and add $2 \mu \mathrm{l}$ plasmid DNA.

7. Pulse at $25 \mu \mathrm{F}, 2.4 \mathrm{kV}, 800 \Omega$.

8. Dilute immediately in $5.0 \mathrm{ml} \mathrm{NZ}$ broth and incubate for 4 hours at $30^{\circ} \mathrm{C}$.

9. Concentrate cells by centrifugation and resuspend in $1.0 \mathrm{ml} \mathrm{NZ}$.

10. Plate $100 \mu \mathrm{l}$ of cells on appropriate antibiotic plates and incubate at $30^{\circ} \mathrm{C}$. 


\section{RESULTS AND DISCUSSION}

The work plan and milestone schedule for the project is illustrated in Figure 2. The duration of the project was continued until March 2006 as the result of a no-cost time extension. The six-month no-cost time extension was requested because of technical difficulties encountered in the isolation of an enzyme capable of selectively cleaving the C-N bond in 2aminobiphenyl. Other tasks in the project were dependent upon the availability of an appropriate enzyme so a time extension was requested and granted to allow enrichment culture experiments to proceed. A bacterial culture capable of metabolizing 2-aminobiphenyl was obtained from these enrichment culture experiments satisfying milestone 3 . The genes that encode for aniline dioxygenase, that catalyzes the removal of the amine group from aniline, were cloned and are available to the project thereby satisfying milestone 4 . The schedule calls for the completion of milestones 5 and 6 by the end of September 2005 and we have not yet completed those milestones. However, we are well on the way to completing these milestones and anticipate doing so within the next quarter. Detailed descriptions of the research results relevant to these milestones are contained in the text below. 
FIGURE 2. WORK PLAN AND MILESTONE SCHEDULE.

\begin{tabular}{|c|c|c|c|c|c|c|c|c|c|c|c|c|c|c|c|}
\hline $\begin{array}{l}\text { Task } \\
\text { No. }\end{array}$ & Task description & $\begin{array}{l}\text { Q1 } \\
10-02 \\
\text { to } \\
12-02\end{array}$ & $\begin{array}{l}\mathrm{Q} 2 \\
1-03 \\
\text { to } \\
3-03\end{array}$ & $\begin{array}{l}\text { Q3 } \\
4-03 \\
\text { to } \\
6-03\end{array}$ & $\begin{array}{l}\text { Q4 } \\
7-03 \\
\text { to } \\
9-03\end{array}$ & $\begin{array}{l}\text { Q5 } \\
10-03 \\
\text { to } \\
12-03\end{array}$ & $\begin{array}{l}\text { Q6 } \\
1-04 \\
\text { to } \\
3-04\end{array}$ & $\begin{array}{l}\text { Q7 } \\
4- \\
04 \\
\text { to } \\
6- \\
04\end{array}$ & $\begin{array}{l}\text { Q8 } \\
7-04 \\
\text { to } \\
9-04\end{array}$ & $\begin{array}{l}\text { Q9 } \\
10-04 \\
\text { to } \\
12-04\end{array}$ & $\begin{array}{l}\text { Q10 } \\
1-05 \\
\text { to } \\
3-05\end{array}$ & $\begin{array}{l}\text { Q11 } \\
4-05 \\
\text { to } \\
6-05\end{array}$ & $\begin{array}{l}\text { Q12 } \\
7-05 \\
\text { to } \\
9-05\end{array}$ & $\begin{array}{l}\text { Q13 } \\
10-05 \\
\text { to } \\
12-05\end{array}$ & $\begin{array}{l}\text { Q14 } \\
1-06 \\
\text { to } \\
3-06\end{array}$ \\
\hline 1 & $\begin{array}{l}\text { Enrichment culture experiments } \\
\text { to isolate } 2 \text {-aminobiphenyl } \\
\text { degraders }\end{array}$ & $\begin{array}{l}\mathrm{X} \\
\mathrm{M} 1\end{array}$ & $\mathrm{X}$ & $\mathrm{X}$ & $\mathrm{X}$ & $\mathrm{X}$ & $\mathrm{X}$ & $\mathrm{X}$ & $\mathrm{X}$ & $\mathrm{X}$ & $\mathrm{X}$ & $\begin{array}{l}\mathrm{X} \\
\mathrm{M} 3\end{array}$ & $\mathrm{X}$ & & \\
\hline 2 & $\begin{array}{ll}\text { Directed evolution } & \text { of } \\
\text { Rhodococcus amidase gene } & \\
\end{array}$ & $\mathrm{X}$ & $\begin{array}{l}\mathrm{X} \\
\mathrm{M} 2\end{array}$ & $\mathrm{X}$ & $\mathrm{X}$ & $\mathrm{X}$ & $\mathrm{X}$ & $\mathrm{X}$ & $\mathrm{X}$ & $\mathrm{X}$ & $\mathrm{X}$ & $\mathrm{X}$ & $\mathrm{X}$ & & \\
\hline 3 & $\begin{array}{l}\text { Construction of pathway for } \mathrm{C}- \\
\mathrm{N} \text { bond cleavage }\end{array}$ & & & & & & $\mathrm{X}$ & $\mathrm{X}$ & $\mathrm{X}$ & $\mathrm{X}$ & $\mathrm{X}$ & $\begin{array}{l}\mathrm{X} \\
\mathrm{M} 4\end{array}$ & $\begin{array}{l}\mathrm{X} \\
\mathrm{M} 5\end{array}$ & $\mathrm{X}$ & $\mathrm{X}$ \\
\hline 4 & $\begin{array}{l}\text { Improving the substrate range } \\
\text { for C-N bond cleavage }\end{array}$ & & & & & & & & & & & $\mathrm{X}$ & $\begin{array}{l}\mathrm{X} \\
\mathrm{M} 6 \\
\end{array}$ & $\begin{array}{l}\mathrm{X} \\
\mathrm{M} 7 \\
\end{array}$ & $\begin{array}{l}\mathrm{X} \\
\mathrm{M} 8 \\
\end{array}$ \\
\hline
\end{tabular}

M1 = Multiple enrichment cultures employing inoculants from various sources will be established to obtain cultures capable of utilizing 2-aminobiphenyl as a sole nitrogen source.

M2 = The Rhodococcus amidase gene will be expressed in E. coli allowing the utilization of benzamide, toluimide, and anthranilimide as sole nitrogen sources.

M3 = A bacterial strain capable of utilizing 2-aminobiphenyl as a sole nitrogen source will be isolated.

M4 = The gene encoding an amidase/deaminase capable of selectively cleaving the $\mathrm{C}-\mathrm{N}$ bond in 2-aminobiphenyl will be cloned and sequenced.

M5 = Construct an operon consisting of the carA genes from Sphingomonas sp. GTIN11 and the gene for 2-aminobiphenyl deaminase.

M6 = The substrate range for the novel C-N bond cleaving pathway will be determined.

M7 = Derivative cultures will be isolated that have improved substrate ranges for the cleavage of C-N bonds.

M8 $=$ The ability of biocatalysts to selectively remove nitrogen from petroleum will be determined. 


\section{Selective Cleavage of Carbon-Nitrogen Bonds: Expression of CarA and AtdA in Rhodococcus}

The development of biocatalysts with improved ability to cleave carbon-nitrogen bonds is being addressed by cloning the genes for carbazole dioxygenase and aniline dioxygenase. The removal of nitrogen from aromatic compounds like carbazole requires the cleavage of two carbon-nitrogen bonds. The cleavage of the first carbon-nitrogen bond is accomplished by the enzyme carbazole dioxygenase while an enzyme capable of selectively cleaving the second carbon-nitrogen bond has not yet been identified, but aniline dioxygenase is an appropriate candidate enzyme. The enzyme carbazole dioxygenase is encoded for by three genes: carAa, carAc, and carAd. The carAacd genes have been cloned and sequenced from several different microbial cultures including Sphingomonas sp. GTIN11 and Pseudomonas resinovorans CA10. While an enzyme that can selectively cleave the second carbon-nitrogen bond in carbazole has not yet been identified a reasonable candidate for such an enzyme is the aniline dioxygenase from Acinetobacter sp. YAA. The genes that encode aniline dioxygenase (atdA1, atdA2, atdA3, atdA4, and atdA5) have been cloned. These genes will be expressed in Rhodococcus erythropolis, a bacterial host that tolerates exposure to petroleum. Gene expression vectors for use in Rhodococcus erythropolis are being constructed from plasmids pEBC26, pSRKgfp, and pRESQ.

\section{Expression of CarA in Rhodococcus}

The carbazole degradation pathway begins with the cleavage of the first carbon-nitrogen bond and the conversion of carbazole to 2-aminobiphenyl-2,3-diol. However, subsequent steps in this carbazole degradation pathway result in the complete destruction of carbazole and the cleavage of the second carbon-nitrogen bond is not accomplished until the molecule is nearly fully degraded and is no longer an aromatic compound. Accordingly we want to keep the first step in this pathway and replace the subsequent steps in the carbazole degradation pathway with a selective cleavage of the carbon-nitrogen bond in 2-aminobiphenyl-2,3-diol. A goal then of our research is to express the genes that encode for the first step of the carbazole degradation pathway in a host that lacks the subsequent steps in the conventional carbazole degradation pathway. The carbazole dioxygenase enzyme (CarA) that converts carbazole to 2aminobiphenyl-2,3-diol is a multicomponent enzyme encoded by three genes; carAacd. The carAacd genes are found adjacent to and in between other carbazole degradation genes in the 
carbazole degradation operons of carbazole-degrading bacteria. Therefore there are two different approaches to obtain functional carAacd genes in the absence of genes for subsequent steps in the carbazole degradation pathway: clone the carAacd genes in a host that lacks other car genes, and inactivate/delete the $\operatorname{car} B$ gene that encodes for the second step in the carbazole degradation pathway. In this project we have performed experiments utilizing both approaches.

The carAacd genes from Sphingomonas sp. GTIN11 and Pseudomonas resinovorans CA10 have been cloned with their native promoters and with alternative promoters in several different vectors capable of replicating in Rhodococcus and E. coli. The vectors used include pEBC26, pSRKgfp, and pRESQ. GTI has modified these vectors to make it more convenient to insert and express genes of interest such as the carAacd genes. An example of a modified vector constructed in this project is pREP45boxBNsiKan.

As we attempt to construct a new metabolic pathway for the selective cleavage of C-N bonds in carbazole and as we attempt to obtain cultures that have improved levels of desulfurization activity it will be increasingly important to have gene expression vectors capable of functioning in Rhodococcus. One of the problems faced in attempts to express genes in Rhodococcus hosts is that many of the genes we are interested in do not have selectable or easily assayed phenotypes. Moreover, genes of interest may come from hosts other than Rhodococcus and may not have promoters that are known to function in these hosts. Accordingly, we have constructed a gene expression vector in which the kanamycin resistance gene from pSRKgfp is used as a selectable genetic marker, but the promoter of the $\mathrm{Kan}^{\mathrm{R}}$ gene has been separated from the structural gene encoding for kanamycin resistance by the insertion of a cloning site, Nsi1. This allows the cloning of genes of interest into the Nsil site so that the gene is placed immediately downstream from the promoter for the $\mathrm{Kan}^{\mathrm{R}}$ gene, and if the $\mathrm{Kan}^{\mathrm{R}}$ gene is functionally expressed then we can be sure that our gene of interest is being transcribed. In other words, we will form a transcriptional fusion with the $\mathrm{Kan}^{\mathrm{R}}$ gene and any gene of interest and since the same promoter will transcribe both the gene of interest and $\operatorname{Kan}^{\mathrm{R}}$ then the selection of the culture for kanamycin resistance ensures that the gene of interest is also being expressed.

This Rhodococcus gene expression vector is named pREP45boxBNsiKan, and an illustration of this plasmid is shown in Figure 3. This vector, pREP45boxBNsiKan, was constructed by replacing the beta-galactosidase gene (Xba/Bgl2 fragment) of pEBC26 with the kanamycin resistance gene of pSRKgfp. However the kanamycin resistance gene was modified 
using PCR to place two additional DNA sequences between the promoter (P45) and the structural gene encoding kanamycin resistance. These two DNA sequences were a boxB imperfect inverted repeat sequence and a Nsil site. The boxB sequence is derived from the $r r n$ operon of Rhodococcus erythropolis IGTS8 and is thought to stabilize mRNA, most probably by providing protection from nucleases. It is hoped that the modified mRNA containing the boxB sequence will have a longer half-life in cells and will therefore result in higher levels of expression as compared to the original $\mathrm{Kan}^{\mathrm{R}}$ gene. The Nsi1 site provides a cloning site for genes of interest allowing them to be inserted so that they are transcribed from the same promoter (P45) as the $\mathrm{Kan}^{\mathrm{R}}$ gene. 


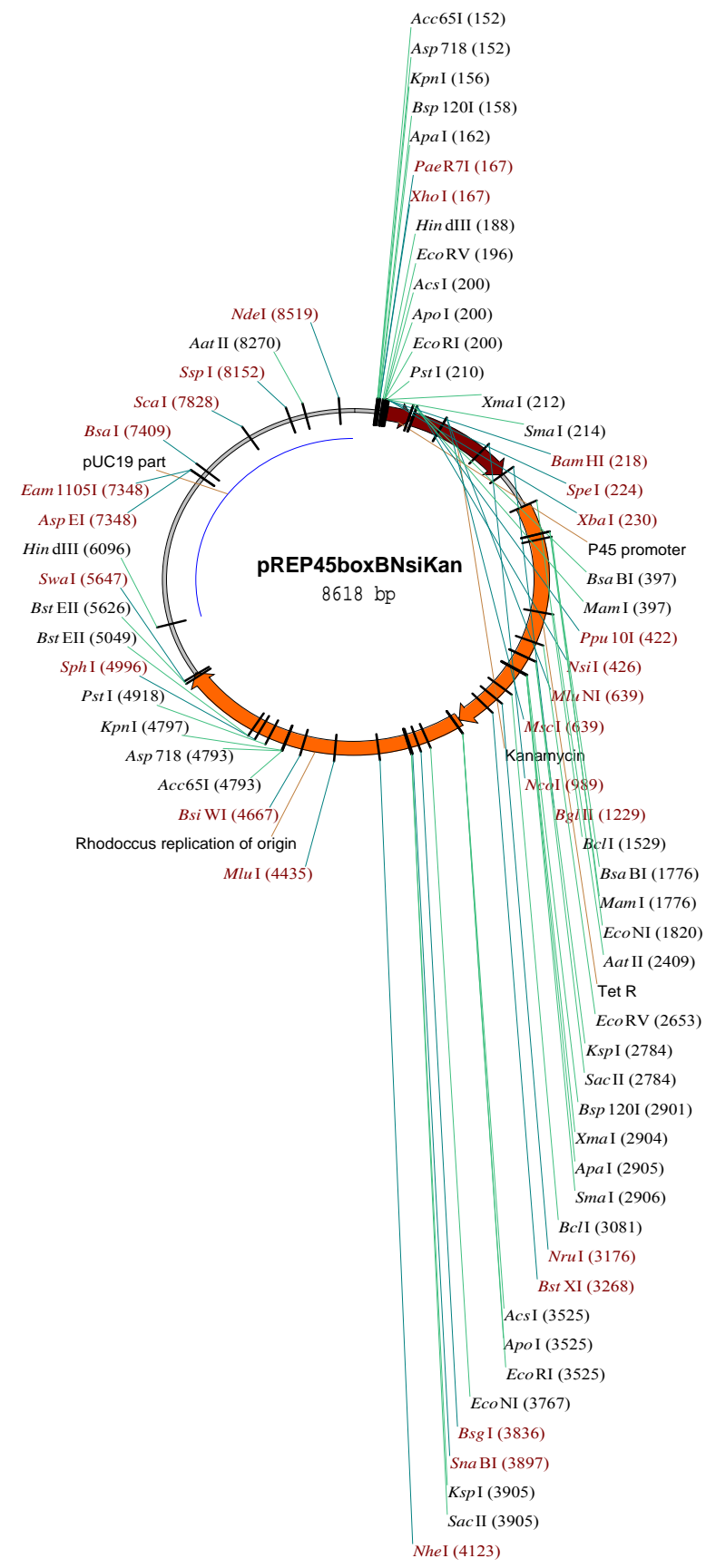

FIGURE 3. MAP OF RHODOCOCCUS EXPRESSION VECTOR PREP45BOXBNSIKAN. 
Construction of a Derivative of Sphingomonas GTIN11 that Lacks CarB and CarC Enzymes

If a derivative of Sphingomonas sp. GTIN11 were available that had a functional CarA enzyme but lacked CarB and/or CarC enzymes it could be used to isolate the enzymes from Pseudomonas sp. GTIN-G4 that encode for a deaminase capable of cleaving the C-N bond in 2aminobiphenyl. Currently Sphingomonas sp. GTIN11 can utilize carbazole as both a source of nitrogen and carbon, but this is because nitrogen is ultimately liberated in the overall degradation of carbazole. What we want is to create a new metabolic pathway that is specific for the cleavage of $\mathrm{C}-\mathrm{N}$ bonds in carbazole. If we retain the carA genes that encode for the cleavage of the first $\mathrm{C}$ $\mathrm{N}$ bond in carbazole to form 2-aminobiphenyl-2,3-diol, but delete one or more of the other genes in the carbazole degradation pathway, then the culture will convert carbazole to 2aminobiphenyl-2,3-diol, but will not degrade it further. Accordingly, we will attempt to delete the $\operatorname{car} B$ and $\operatorname{car} C$ genes. This will be accomplished by the steps of: obtaining a DNA fragment containing the carB and carC genes as well as flanking regions, replacing the carB and carC genes with the kanamycin resistance gene from pSRKgfp, introduce this non-replicating DNA fragment into Sphingomonas sp. GTIN11 and select for kanamycin resistance to isolate derivatives of GTIN11 (resulting from homologous recombination at flanking DNA regions) that contain a deletion of $\operatorname{carB}$ and $\operatorname{carC}$. Once a derivative of GTIN11 is available that lacks carB and $\operatorname{car} C$ we can better use this host to clone deaminase genes that may be capable of utilizing 2aminobiphenyl-2,3-diol as a substrate.

The strategy to construct a derivative of Sphingomonas GTIN11 that possesses a functional CarA enzyme (encoded by carAa, carAc, and carAd), but lacks subsequent steps in the carbazole degradation pathway is pictured in Figure 4. After obtaining kanamycin-resistant derivatives as pictured in Figure 4 we have so far been unable to demonstrate the presence of a functional CarA enzyme. This may be due to a disruption of the expression of the carAc gene resulting from the deletion of the $\operatorname{carB}$ and $\operatorname{car} C$ genes. 

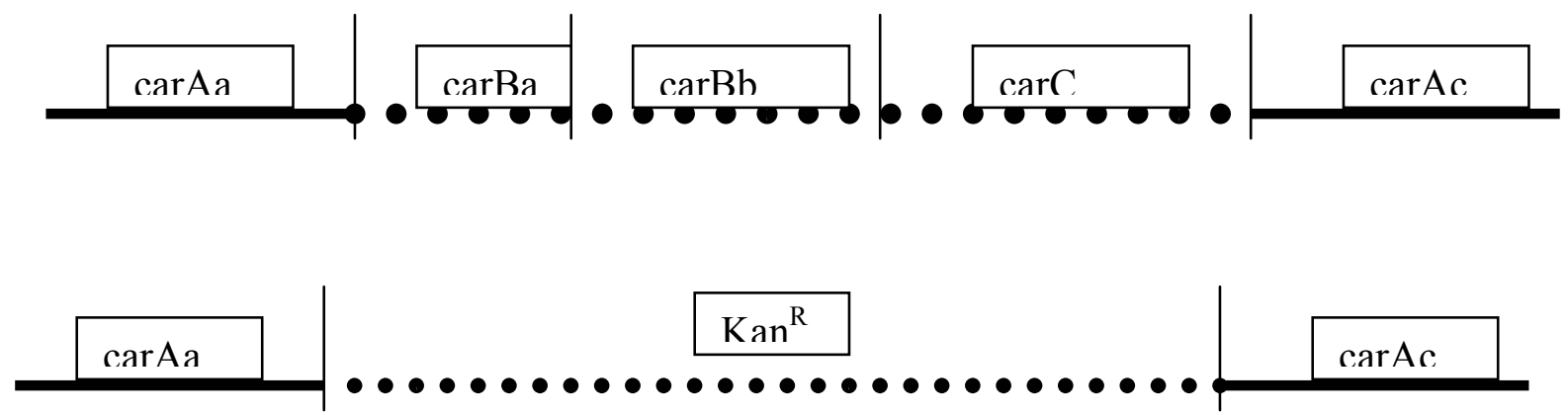

FIGURE 4. STRATEGY FOR THE REPLACEMENT OF THE CARBA, CARBB, AND CARC GENES OF SPHINGOMONAS GTIN11 WITH A GENE ENCODING KANAMYCIN RESISTANCE. 


\section{Isolation of 2ABP Degrading Bacterial Culture}

The selective removal of nitrogen from petroleum can complement hydrotreatment for upgrading petroleum and create petroleum products that have better stability. It is important to note that recent investigations reported in the literature [3] show that the typical biochemical pathways for the metabolism of carbazole are not suitable for upgrading petroleum. 2ABP is converted to 2-aminobiphenyl-2,3-diol by the first step in previously characterized carbazole degradation pathways. It has been speculated that the cleavage of one of the two C-N bonds in carbazole, and related compounds, could be sufficient to allow upgrading of petroleum in combination with hydrotreating. However, the study by Bressler et al. [2, 3] demonstrated that compounds such as 2-aminobiphenyl-2,3-diol are transformed by the hydrotreatment process resulting in ring closure, condensation, and polymerization. Deamination was not observed. The implication of this for the current project is that biochemical cleavage of both $\mathrm{C}-\mathrm{N}$ bonds in carbazole is required for upgrading petroleum and previously characterized biochemical pathways for carbazole biodegradation are not appropriate. The newly isolated 2ABP-degrading culture Pseudomonas sp. GTIN-G4 may contain an enzyme capable of cleaving the C-N bond in 2-aminobiphenyl-2,3-diol that could be used to help construct the first biochemical pathway for the selective removal of nitrogen from carbazole. Accordingly, the metabolites of $2 \mathrm{ABP}$, and related compounds, formed by Pseudomonas sp. GTIN-G4 were investigated. 
FIGURE 5. STRUCTURE OF ORGANONITROGEN COMPOUNDS USED IN GROWTH TESTS WITH PSEUDOMONAS SP. GTIN-G4

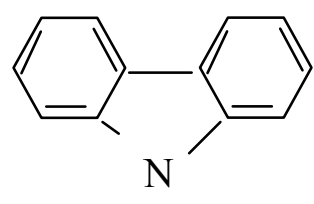

C.arhazole

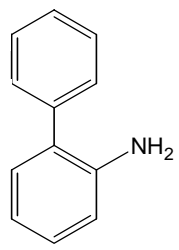

2-aminobiphenyl

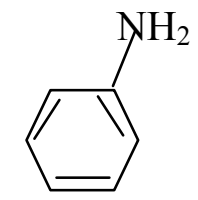

Aniline

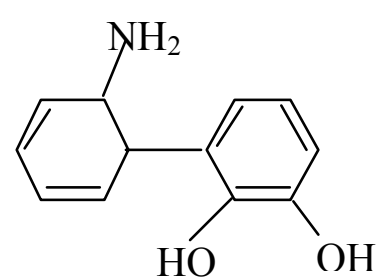

2-aminohinhenvl-2.3-diol

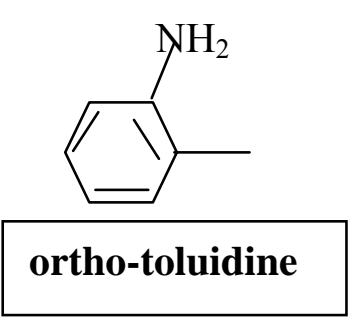

$\mathrm{NH}_{2}$

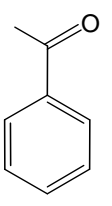

Benzamide 
Pseudomonas sp. GTIN-G4 was isolated based on its ability to grow in a defined mineral salts medium containing 2-aminibiphenyl (2ABP) as the sole nitrogen source. Initial microbial growth tests utilized a stock solution of 100 millimolar 2ABP dissolved in ethanol. Growth experiments employed a final concentration of $1 \mathrm{mM} 2 \mathrm{ABP}$ in MMN medium incubated aerobically at $30^{\circ} \mathrm{C}$. Pseudomonas sp. GTIN-G4 grew under these conditions and appeared to be utilizing $2 \mathrm{ABP}$ as a sole source of nitrogen and carbon. After repeated testing of the culture it became clear that ethanol was a good carbon source for the growth of the culture. Subsequent growth tests exclusively used crystals or neet liquids of test compounds rather than stock solutions dissolved in ethanol.

The results of a typical growth test are shown in Table 2 in which the ability of organic and inorganic nitrogen sources were tested to see if they support the aerobic growth of Pseudomonas sp. GTIN-G4. The results appear to indicate that carbazole, 2ABP, o-toluidine, and diphenylamine can be used as nitrogen sources but not as carbon sources. However, unexpected growth was also observed when ethanol was used as a carbon source, but no nitrogen source was provided. Pseudomonas sp. GTIN-G4 is a fragile culture that frequently fails to yield growth upon subculturing so that growth test must be repeated multiple times before it can be concluded with confidence that a given condition will allow growth of this culture. This is why it was not initially observed that Pseudomonas sp. GTIN-G4 could grow in the absence of a specifically supplied organic or inorganic nitrogen compound. However, repeated testing yielded the results summarized in Table 2. The test substrates $2 \mathrm{ABP}$, o-toluidine, and diphenylamine were transformed to colored products in growth experiments and these colored products were not observed in sterile controls. It was clear then that Pseudomonas sp. GTIN-G4 was metabolizing 2ABP, o-toluidine, and diphenylamine but it was not clear if these compounds were serving as nitrogen sources for the growth of the culture. 
Table 2. Aerobic Growth of Pseudomonas sp. GTIN-G4 with Various Nitrogen Sources

\begin{tabular}{|l|l|l|l|}
\hline Carbon Source & Nitrogen Source & Growth & Color of Sample \\
\hline None & None & - & clear \\
\hline ethanol & None & ++ & gray \\
\hline ethanol & $\mathrm{NH}_{4} \mathrm{Cl}$ & ++ & gray \\
\hline ethanol & $\mathrm{NH}_{4} \mathrm{NO}_{3}$ & ++ & gray \\
\hline ethanol & carbazole & ++ & gray \\
\hline ethanol & 2-aminobiphenyl & ++ & copper/brown \\
\hline ethanol & o-toluidine & ++ & light brown \\
\hline ethanol & diphenylamine & ++ & slightly purple \\
\hline None & $\mathrm{NH}_{4} \mathrm{NO}_{3}$ & - & clear \\
\hline None & carbazole & - & clear \\
\hline None & 2 -aminobiphenyl & - & clear \\
\hline
\end{tabular}


The growth of the culture in the apparent absence of a nitrogen source suggested the possibility that the culture could fix atmospheric nitrogen. To investigate this possibility, growth tests were performed in sealed serum bottles using pure oxygen or air as the headspace gas. Multiple growth experiments were performed and the results are summarized in Table 3, which illustrated that no growth was obtained when pure oxygen was used while air did yield growth supporting the conclusion that Pseudomonas sp. GTIN-G4 can fix $\mathrm{N}_{2}$ gas. However, the failure of the culture to grow in the presence of pure oxygen even when $\mathrm{NH}_{4} \mathrm{Cl}$ or $\mathrm{NH}_{4} \mathrm{NO}_{3}$ were provided raised the possibility that perhaps pure oxygen was toxic to the culture.

Table 3. Growth of Pseudomonas sp. GTIN-G4 in the Absence of Nitrogen Gas

\begin{tabular}{|l|l|l|l|}
\hline Carbon Source & Nitrogen Source & Headspace Gas & Growth \\
\hline None & None & $\mathrm{O}_{2}$ & - \\
\hline ethanol & None & $\mathrm{O}_{2}$ & - \\
\hline ethanol & $\mathrm{NH}_{4} \mathrm{Cl}$ & $\mathrm{O}_{2}$ & - \\
\hline ethanol & $\mathrm{NH}_{4} \mathrm{NO}_{3}$ & $\mathrm{O}_{2}$ & - \\
\hline ethanol & 2-aminobiphenyl & $\mathrm{O}_{2}$ & - \\
\hline ethanol & o-toluidine & $\mathrm{O}_{2}$ & - \\
\hline ethanol & diphenylamine & $\mathrm{O}_{2}$ & - \\
\hline None & 2-aminobiphenyl & $\mathrm{O}_{2}$ & - \\
\hline None & None & Air & - \\
\hline ethanol & None & Air & ++ \\
\hline ethanol & 2-aminobiphenyl & Air & ++ \\
\hline
\end{tabular}

This possibility was investigated in experiments summarized in Table 4 in which the growth of E. coli and Pseudomonas sp. GTIN-G4 were compared using various concentrations of oxygen. To achieve the desired concentration of oxygen the sealed serum bottles were first sparged for 2 minutes with pure oxygen then the required volume of gas was removed and replaced with helium. However, growth of Pseudomonas sp. GTIN-G4 was not obtained even with $25 \%$ oxygen, which is very near the oxygen concentration in air. Therefore some experiments were performed in which the sealed serum bottles were first sparged with helium and then the required volume of gas was removed and replaced by oxygen in order to achieve the 
desired oxygen concentration. As shown in Table 4, Pseudomonas sp. GTIN-G4 is sensitive to exposure to pure oxygen while E. coli is not.

Table 4. Growth of Pseudomonas sp. GTIN-G4 and Escherichia coli with Various Concentrations of Oxygen.

\begin{tabular}{|c|c|c|c|}
\hline Bacterial Culture & Media composition & Headspace Gas & Growth \\
\hline GTIN-G4 & $\begin{array}{l}\text { MMN,ethanol, } \\
\mathrm{NH}_{4} \mathrm{NO}_{3}\end{array}$ & $100 \% \mathrm{O}_{2}$ & - \\
\hline GTIN-G4 & $\begin{array}{l}\text { MMN,ethanol, } \\
\mathrm{NH}_{4} \mathrm{NO}_{3}\end{array}$ & $50 \% \mathrm{O}_{2}$ & - \\
\hline GTIN-G4 & $\begin{array}{l}\text { MMN,ethanol, } \\
\mathrm{NH}_{4} \mathrm{NO}_{3}\end{array}$ & $25 \% \mathrm{O}_{2}$ & - \\
\hline GTIN-G4 & $\begin{array}{l}\text { MMN,ethanol, } \\
\mathrm{NH}_{4} \mathrm{NO}_{3}\end{array}$ & $20 \% \mathrm{O}_{2}, \mathrm{He}$ first & + \\
\hline E. coli & L Broth & $100 \% \mathrm{O}_{2}$ & ++ \\
\hline E. coli & L Broth & $50 \% \mathrm{O}_{2}$ & ++ \\
\hline E. coli & L Broth & $25 \% \mathrm{O}_{2}$ & ++ \\
\hline E. coli & L Broth & $20 \% \mathrm{O}_{2}, \mathrm{He}$ first & ++ \\
\hline
\end{tabular}


To more fully define the growth capabilities of Pseudomonas sp. GTIN-G4 experiments were performed using cultures initially sparged with helium and subsequently adjusted so the gas composition was $20 \%$ oxygen. The results of such tests are shown in Table 5 where it is observed that when growth of Pseudomonas sp. GTIN-G4 occurs in the absence of $\mathrm{N}_{2}$ gas colored metabolites of 2ABP, o-toluidine, or diphenylamine are not observed. Growth of Pseudomonas sp. GTIN-G4 with air is required for the production of colored products derived from organonitrogen substrates.

Table 5. Growth of Pseudomonas sp. GTIN-G4 with Various Organonitrogen Compounds in the Absence of nitrogen Gas

\begin{tabular}{|l|l|l|}
\hline Nitrogen Source & Headspace Gas & Growth \\
\hline $\mathrm{NH}_{4} \mathrm{Cl}$ & $20 \% \mathrm{O}_{2} / 80 \% \mathrm{He}$ & ++ , clear \\
\hline $\mathrm{NH}_{4} \mathrm{NO}_{3}$ & $20 \% \mathrm{O}_{2} / 80 \% \mathrm{He}$ & ++ , clear \\
\hline $\mathrm{NH}_{4} \mathrm{NO}_{3}, 2$-aminobiphenyl & $20 \% \mathrm{O}_{2} / 80 \% \mathrm{He}$ & ++ , clear \\
\hline $\mathrm{NH}_{4} \mathrm{NO}_{3}$, o-toluidine & $20 \% \mathrm{O}_{2} / 80 \% \mathrm{He}$ & ++ , clear \\
\hline $\mathrm{NH}_{4} \mathrm{NO}_{3}$ diphenylamine & $20 \% \mathrm{O}_{2} / 80 \% \mathrm{He}$ & ++ , clear \\
\hline 2-aminobiphenyl & $20 \% \mathrm{O}_{2} / 80 \% \mathrm{He}$ &,- clear \\
\hline o-toluidine & $20 \% \mathrm{O}_{2} / 80 \% \mathrm{He}$ & - , clear \\
\hline diphenylamine & $20 \% \mathrm{O}_{2} / 80 \% \mathrm{He}$ & - , clear \\
\hline 2-aminobiphenyl & Air & ++ , copper/brown \\
\hline o-toluidine & Air &,++ light brown \\
\hline diphenylamine & Air & ++ , slightly purple \\
\hline
\end{tabular}

Pseudomonas sp. GTIN-G4 metabolizes 2-aminobiphenyl, diphenylamine, o-toluidine, and aniline in liquid cultures to produce colored metabolites that are not observed in sterile controls or with cultures of other bacteria incubated with these substrates. GC-MS analyses identified some unique products that appear to result from the metabolism of Pseudomonas sp. GTIN-G4. Mass spectral analysis was performed on aqueous extract samples in an attempt to identify potential biodegradation byproducts formed by Pseudomonas sp. GTIN-G4 from 2aminobiphenyl, diphenylamine, and o-toluidine. Compounds were found in all three sample types suggesting a substitution of a hydrogen on the nitrogen atom with a CHO group. The proposed structure was confirmed for the diphenylamine by comparing it to a standard of N,Ndiphenylformamide. The structures related to the 2-aminobiphenyl and o-toluidine samples are 
based on the similarities of their mass spectra to that of N,N-diphenylformamide. GC-MS data illustrating the formaldehyde-modified derivatives of $2 \mathrm{ABP}$, o-toluidine, and diphenylamine produced by Pseudomonas sp. GTIN-G4 are shown in Figures 6, and 7 respectively. Similar results were also obtained for the metabolism of aniline by Pseudomonas sp. GTIN-G4 (data not shown).

The microbial modification of chemical compounds by the addition of a formaldehyde group is without precedent. The addition of methyl groups to detoxify organic and metal compounds is a well-known capability of many microorganisms and fungi [1]. Moreover, the addition of a methyl group to a nitrogen atom in place of a hydrogen atom, such as the biochemical conversion of pyridine to N-methylpyridine, is well known. Similarly, the addition of carboxyl groups to organic compounds by aerobic [4] and anaerobic microorganisms [28], and the addition of carbonyl groups [6] are described in the literature. However, there are no reports of microbial cultures that are capable of modifying organic compounds by the addition of formaldehyde groups except in the degradation of formaldehyde where formaldehyde reacts with ribulose-5-phosphate to form D-arabino-3-hexulose-6-phosphate, which is subsequently isomerized to fructose-6-phosphate [22]. The formation of $\mathrm{N}$-formamide derivatives of 2aminobiphenyl, diphenylamine, and o-toluidine is a unique capability of Pseudomonas sp. GTIN-G4, but it is not clear if this will facilitate the eventual removal of nitrogen from these molecules. Since Pseudomonas sp. GTIN-G4 is capable of fixing nitrogen it is difficult to determine if organically bound nitrogen is liberated in microbiological experiments that include this culture. Accordingly it does not appear to be worthwhile to continue an investigation of this culture, as it does not clearly aid in the removal of nitrogen from compounds typically present in petroleum. 
FIGURE 6. MASS SPECTRA OF 2-AMINOBIPHENYL AND A METABOLITE PRODUCED BY PSEUDOMONAS SP. GTIN-G4.

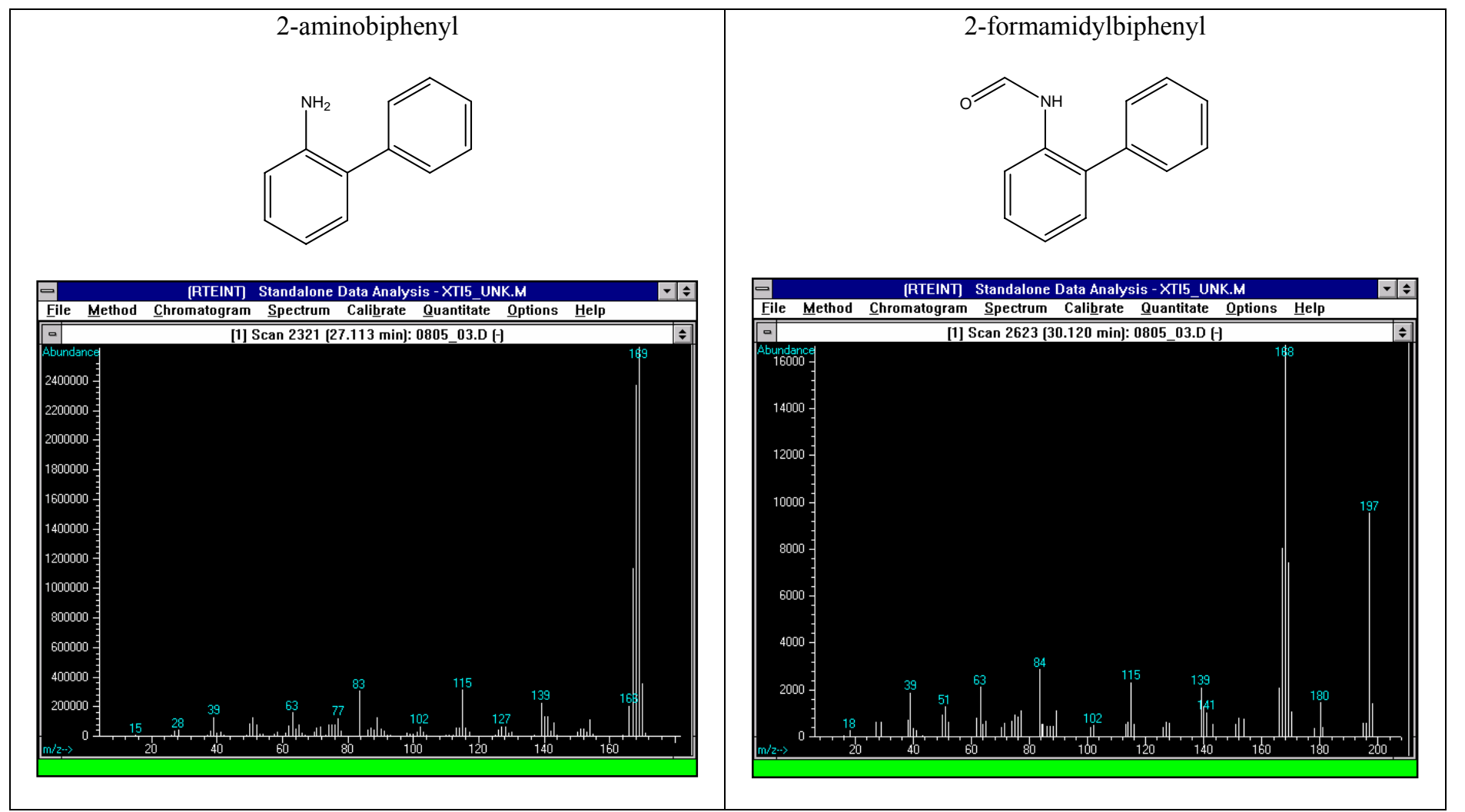


FIGURE 7. MASS SPECTRA OF O-TOLUIDINE AND DIPHENYLAMINE AND THE CORRESPONDING METABOLITES PRODUCED BY PSEUDOMONAS SP. GTIN-G4.

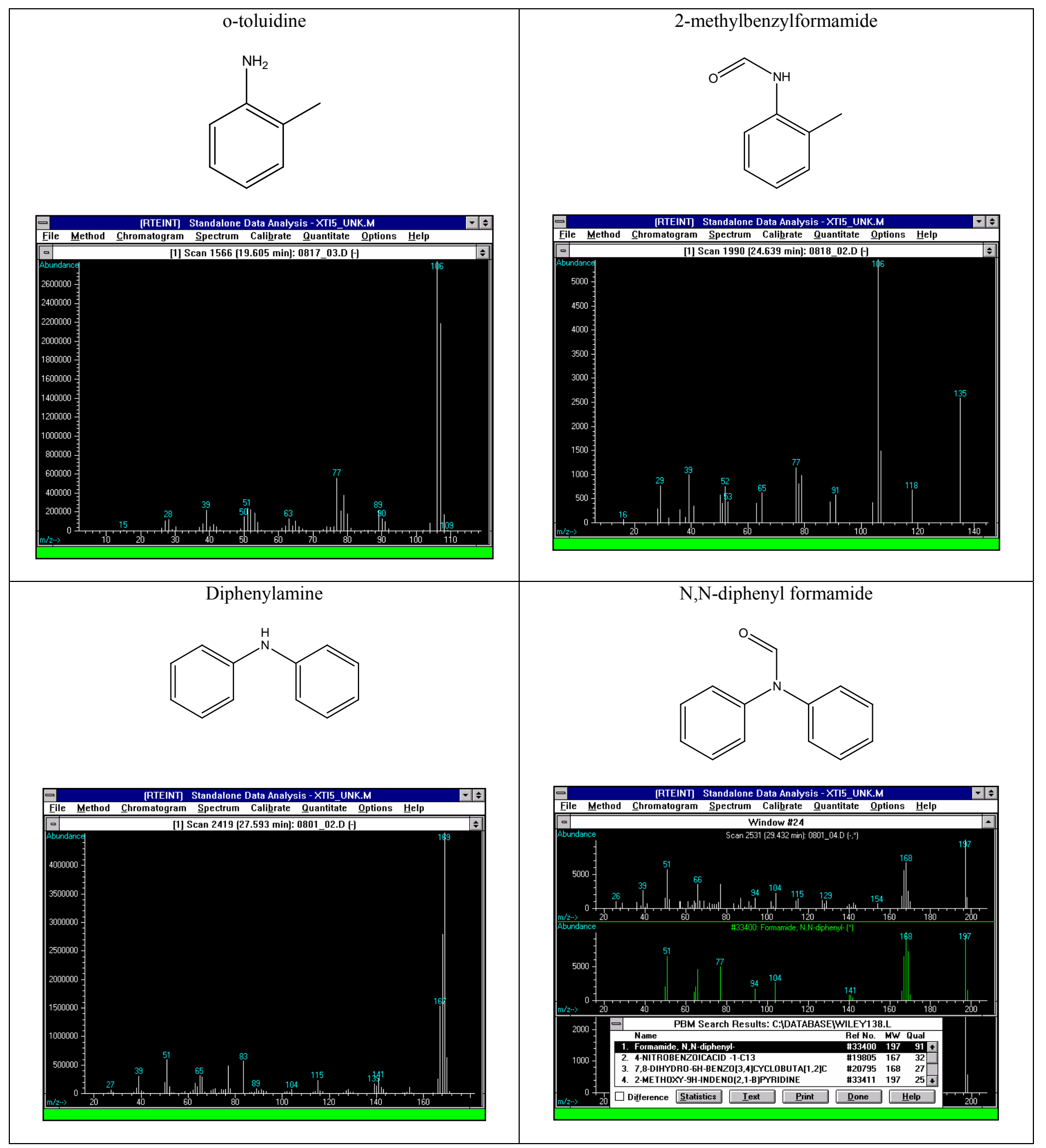




\section{Cloning and Expression of the atdA1-5 Genes for Aniline Dioxygenase}

Since an enzyme capable of directly cleaving the carbon-nitrogen bond in 2aminobiphenyl has not yet been isolated then the best alternative is aniline dioxygenase. Aniline dioxygenase, AtdA, is a multicomponent enzyme isolated from Acinetobacter sp. Strain YAA involved in the simultaneous deamination and oxygenation of aniline [10] and o-toluidine, see Figure 8. The genes encoding for AtdA was found to have 5 open reading frames (ORFs), atdA1A5.

(a)

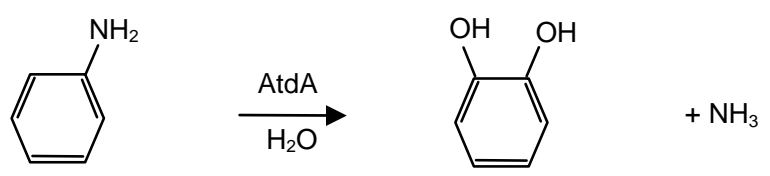

(b)

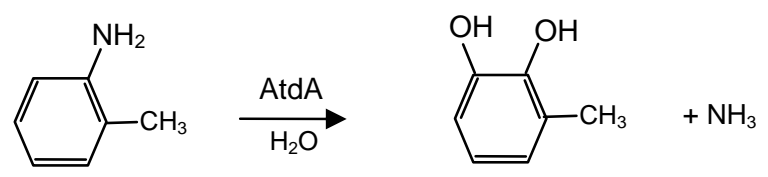

FIGURE 8. DEAMINATION AND OXYGENATION OF (A) ANILINE AND (B) OTOLUIDINE BY ATDA.

The plasmid pAS93, consisting of the five atdA open reading frames (ORFs) cloned into a pUC19 vector, [10] was obtained from Dr Takeo in the Department of Applied Chemistry, Himeji Institute of Technology, Japan. E. coli JM109 was used as host for the pAS93 plasmid.

The atdA1-5 genes will be cloned and expressed in Rhodococcus hosts using the same vectors described above for expression of carAacd genes. By simultaneously expressing the carAacd and the atdA1-5 genes in the same host it is hoped that natural selection for growth with carbazole as a sole source of nitrogen will result in the creation of a new metabolic pathway for the selective cleavage of both carbon-nitrogen bonds in carbazole. 


\section{CONCLUSIONS AND FUTURE EXPERIMENTS}

Enrichment culture experiments designed to isolate a culture capable of cleaving the carbon-nitrogen bond in 2-aminobiphenyl, and thus being capable of providing an enzyme for the cleavage of the second carbon-nitrogen bond in carbazole, resulted in the isolation of a unique microbial culture Pseudomonas sp. GTIN-G4. Pseudomonas sp. GTIN-G4 is capable of metabolizing 2-aminobiphenyl and related compounds, but does not appear to be capable of cleaving the carbon-nitrogen bond. Instead it has the unprecedented ability to modify organonitrogen compounds by replacing a hydrogen bound to the nitrogen atom with a formaldehyde group. This is a very interesting metabolic ability, but it does not allow the removal of nitrogen from organonitrogen compounds so this culture will not be examined further. The time remaining in this project does not allow continued enrichment culture experiments to isolate a culture that contains an enzyme capable of selectively cleaving the C-N bond in 2-aminobiphenyl. It is not known how long such an effort might take and if it can be successful within the time remaining in the project. Therefore we will focus on the use of enzymes/genes that are available to the project and known to selectively cleave $\mathrm{C}-\mathrm{N}$ bonds in carbazole or molecules chemically related to carbazole.

Future experiments will focus on using molecular genetics to obtain derivatives of Rhodococcus erythropolis IGTS8 that are more efficient biocatalysts for the removal of nitrogen from petroleum. Specifically, the carAacd genes from Sphingomonas sp. GTIN11 and/or Pseudomonas resinovorans CA10 will be expressed simultaneously with the atdA1-5 genes from Acinetobacter sp. YAA in a Rhodococcus host. The simultaneous expression of these two sets of genes in the same host may allow for the creation of a novel biochemical pathway for the selective cleavage of both $\mathrm{C}-\mathrm{N}$ bonds in carbazole. 


\section{REFERENCES}

1. Bentley, R. and T.G. Chasteen (2002) Microbial methylation of metalloids: arsenic, antimony, and bismuth. Microbiol Mol Biol Rev. 66: 250-271.

2. Bressler, D.C. and P.M. Fedorak (2000) Bacterial metabolism of fluorene, dibenzofuran, dibenzothiophene, and carbazole. Can J Microbiol. 46: 397-409.

3. Bressler, D.C., and M. R. Gray (2002) Hydrotreating chemistry of model products from bioprocessing of carbazoles. Energy \& Fuels. 16: 1076-1086.

4. Clark, D.D. and S.A. Ensign (1999) Evidence for an inducible nucleotide-dependent acetone carboxylase in Rhodococcus rhodochrous B276. J Bacteriol. 181: 2752-2758.

5. Creaser, C.S., F. Krokos, K. E. O'neill, M. J. C. Smith and P. G. McDowell (1993) Selective chemical ionization of nitrogen and sulfur heterocycles in petroleum fractions by ion trap mass spectrometry. J. American Society of Mass Spectrometry. 4: 322-326.

6. Cuny, C., L. Dukan, L. Fraysse, M. Ballesteros, and S. Dukan (2005) Investigation of the first events leading to loss of culturability during Escherichia coli starvation: future nonculturable bacteria form a subpopulation. J Bacteriol. 187: 2244-2248.

7. d'Abusco, A.S., S. Ammendola, R. Scandurra, and L. Politi (2001) Molecular and biochemical characterization of the recombinant amidase from hyperthermophilic archaeon Sulfolobus solfataricus. Extremophiles. 5: 183-192.

8. Drew, L.J., Petroleum, in Kirk-Othmer Encyclopedia of Chemical Technology, J.I. Kroschwitz and M. Howe-Grant, Editors. 1996. p. 342-476.

9. Du, X., W. Wang, R. Kim, H. Yakota, H. Nguyen, and S.-H. Kim (2001) Crystal structure and mechanism of catalysis of a pyrazinamidase from Pyrococcus horikoshii. Biochemistry. 40: 14166-14172.

10. Fujii, T., M. Takeo, and Y. Maeda (1997) Plasmid-encoded genes specifying aniline oxidation from Acinetobacter sp. strain YAA. Microbiology. 143: 93-99.

11. Gieg, L.M., A. Otter, and P. M. Fedorak (1996) Carbazole degradation by Pseudomonas LD2: Metabolic characteristics and identification of some metabolites. Environ. Sci. Technol. 30: 575-585.

12. Hegedus, L.L., and McCabe, R. W. (1981) Catalyst Poisoning. Catalyst Reveiw. 23: 377-476.

13. Hsu, C.S., K. Qian, and W. K. Robbins (1994) Nitrogen speciation of polar petroleum compounds by compound class separation and on-line liquid chromatography-mass spectometry (LC-MS). J. High Resolution Chromatography. 17: 271-276.

14. Kassler, P., World energy demand outlook, in Energy exploration and exploitation, G. Jenkins, Editor. 1996, Multi-Science Publishing Co: Berkshire, United Kingdom. p. 229-242.

15. Kilbane, J.J., 2nd, R. Ranganathan, L. Cleveland, K.J. Kayser, C. Ribiero, and M.M. Linhares (2000) Selective removal of nitrogen from quinoline and petroleum by Pseudomonas ayucida IGTN9m. Appl Environ Microbiol. 66: 688-693.

16. Kilbane, J.J., A. Daram, J. Abbasian, and K. J. Kayser (2002) Isolation and characterization of a carbazole degrading bacterium Sphingomonas sp. GTIN11. Appl Environ Microbiol. Submitted. 
17. Kirimura, K., H. Nakagawa, K. Tsuji, K. Matsuda, R. Kurane, and S. Usami (1999) Selective and continuous degradation of carbazole contained in petroleum oil by resting cells of Sphingomonas sp. CDH-7. Biosci Biotechnol Biochem. 63: 1563-1568.

18. Kobayashi, T., R. Kurane, K. Nakajima, Y. Nakamura, K. Kirimura, and S. Usami (1995) Isolation of bacteria degrading carbazole under microaerobic conditions, i.e. nitrogen gas substituted conditions. Biosci Biotechnol Biochem. 59: 932-933.

19. Mushrush, G.W., E. J. Beal, D. R. Hardy, and J. M. Hughes (1999) Nitrogen compound distribution in middle distillate fuels derived from petroleum, oil shale, and tar sand sources. Fuel Processing Technology. 61: 197-201.

20. Nojiri, H., J.W. Nam, M. Kosaka, K.I. Morii, T. Takemura, K. Furihata, H. Yamane, and T. Omori (1999) Diverse oxygenations catalyzed by carbazole 1,9adioxygenase from Pseudomonas sp. Strain CA10. J Bacteriol. 181: 3105-3113.

21. Oichiyama, N., T. Omori, and T. Kodama (1993) Biodegradation of carbazole by Pseudomonas spp.CA06 and CA10. Biosci. Biotech. Biochem. 57: 455-460.

22. Orita, I., H. Yurimoto, R. Hirai, Y. Kawarabayasi, Y. Sakai, and N. Kato (2005) The archaeon Pyrococcus horikoshii possesses a bifunctional enzyme for formaldehyde fixation via the ribulose monophosphate pathway. J Bacteriol. 187: 3636-3642.

23. Ouchiyama, N., S. Miyachi, and T. Omori (1998) Cloning and Nucleotide Sequence of Carbazole Catabolic Genes from Pseudomonas stutzeri OM1, Isolated from Activated Sludge. J. General Microbiology. 44: 57-63.

24. Reeson, S. (1996) Heavy fuel oil: Acceptable? Available? Affordable? Energy World. 235: 9-11.

25. Sato, S.I., J.W. Nam, K. Kasuga, H. Nojiri, H. Yamane, and T. Omori (1997) Identification and characterization of genes encoding carbazole 1,9a- dioxygenase in Pseudomonas sp. strain CA10. J Bacteriol. 179: 4850-4858.

26. Sato, S.I., N. Ouchiyama, T. Kimura, H. Nojiri, H. Yamane, and T. Omori (1997) Cloning of genes involved in carbazole degradation of Pseudomonas sp. strain CA10: nucleotide sequences of genes and characterization of meta- cleavage enzymes and hydrolase. J Bacteriol. 179: 4841-4849.

27. Schneider, J., R.J. Grosser, K. Jayasimhulu, W. Xue, B. Kinkle, and D. Warshawsky (2000) Biodegradation of carbazole by Ralstonia sp. RJGII.123 isolated from a hydrocarbon contaminated soil. Can J Microbiol. 46: 269-277.

28. Schuhle, K. and G. Fuchs (2004) Phenylphosphate carboxylase: a new C-C lyase involved in anaerobic phenol metabolism in Thauera aromatica. J Bacteriol. 186: 4556-4567.

29. Shepherd, J.M. and G. Lloyd-Jones (1998) Novel carbazole degradation genes of Sphingomonas CB3: sequence analysis, transcription, and molecular ecology. Biochem Biophys Res Commun. 247: 129-135.

30. Shotbolt-Brown, J., D.W. Hunter, and J. Aislabie (1996) Isolation and description of carbazole-degrading bacteria. Can J Microbiol. 42: 79-82.

31. Speight, J.G., The Chemistry and Technology of Petroleum. 1980, New York: Marcel Dekker, Inc.

32. Technology, I.o.G. (1991) Energy Statistics. Energy Statistics. 14. 